Published as: Oosthuizen, I., Dada, S., Bornman, J., \& Koul, R. (2017). Message banking: Perceptions of persons with motor neuron disease, significant others and clinicians. International Journal of Speech-Language Pathology, 1-10.

\title{
Message banking: Perceptions of persons with motor neuron disease, significant others and clinicians
}

\author{
Imke Oosthuizen $^{1}$, Shakila Dada ${ }^{1}$, Juan Bornman $^{1}$, Rajinder Koul ${ }^{2}$ \\ ${ }^{1}$ Centre for Augmentative and Alternative Communication, University of Pretoria, South Africa \\ ${ }^{2}$ Chair in the Department of Speech, Language, and Hearing Sciences, Texas Tech University, USA.
}

This study was supported by University of Pretoria Postgraduate Research Bursary. The authors would like to thank all the participants of the study.

Correspondence regarding this article should be addressed to Shakila Dada, Centre for Augmentative and Alternative Communication, University of Pretoria, Pretoria, 0028. E-mail: shakila.dada@up.ac.za

\begin{abstract}
Purpose: Message banking is an intervention strategy that has the potential to facilitate effective communication for people with motor neuron disease when their condition deteriorates to the extent that they cannot communicate using natural speech. The aim of the current study was to determine and compare the perceptions on message banking of three stakeholder groups, namely persons with motor neuron disease, their significant others and speech-language pathologists.
\end{abstract}


Method: A comparative group survey design was used. Participants listened to a short presentation about message banking, after which they individually completed a questionnaire.

Result: Although most participants reported that they had never heard of message banking, all were interested in it. The survey results revealed statistically significant differences between the various groups of stakeholders regarding the relevance of message banking and types of messages to bank.

Conclusion: The study concluded that there is limited awareness about message banking amongst all participant groups.

Keywords: amyotrophic lateral sclerosis, communication messages, augmentative and alternative communication.

Motor neuron disease (MND), an umbrella term for a subset of degenerative neurological diseases, is known as amyotrophic lateral sclerosis (ALS) in Europe and the United States. It is a rare but rapidly progressive neurological condition characterised by motor neuron degeneration of the central nervous system, and is inclusive of frontal temporal impairment in some cases (Hardiman, van den Berg \& Kiernan, 2011). The majority of persons who develop MND are in the age group 45 to 65 years (Murphy, 2004). The worldwide estimated prevalence of MND is six in 100000 people (Henning, 2012). The life expectancy for patients with MND is generally between two and five years (Doyle \& Philips, 2001). However, prolonged survival has recently become evident due to relatively more effective management strategies (Pupillo, Mesinna, Logroscino \& Beghi, 2014).

It is estimated that $95 \%$ of persons with MND gradually lose their ability to communicate through natural speech (Beukelman, Fager \& Nordess, 2011; Mckelvey, Evans, Kawai \& Beukelman, 2012). The loss or anticipated loss of speech and communication is 
often perceived as being stripped of humanity, and having to face this loss when confronted with a terminal illness is even more challenging (Brownlee \& Bruenning, 2012).

As the disease progresses, the majority of persons with MND experience a motor speech disorder of mixed dysarthria, specifically flaccid-spastic type. Their speech is often characterised by slow and effortful speech comprising short phrases, imprecise consonants, hypernasal quality, inappropriate pauses, reduced level and range for pitch and loudness, as well as a strained-strangled voice quality (Mckelvey et al., 2012). Persons with MND are, therefore, candidates for AAC intervention and they can typically benefit from AAC intervention strategies and techniques (Beukelman et al., 2011). AAC intervention also has potential to meet the needs of palliative care and can improve the quality of life of the person with MND by assisting with decision making, optimising function and allowing for opportunities for personal growth (Bongioanni, 2012).

A qualitative study conducted over the course of four years on the use and acceptance of AAC by 50 persons with MND reported that $96 \%$ accepted AAC, which was described as obtaining the AAC technology, enrolling for training, and using the technology. Altogether $90 \%$ of them accepted and used the technology immediately, $6 \%$ did so after a little while, and only two participants (4\%) rejected AAC (Ball, Beukelman \& Pattee, 2004). Beukelman, Fager, Ball and Dietz (2007) reported similar findings and found that acceptance and use of AAC had increased for persons with MND over the decade from 1997 to 2007. However, limited data are available about the efficacy of specific AAC strategies and techniques employed during the various stages of MND.

In a qualitative study spanning three years and involving 15 persons with MND and their closest communication partners, Murphy (2004) captured the use and interplay of different modes of communication, including speech, non-verbal methods, and AAC on 
video. Murphy found that AAC strategies were less successful than had been expected and attributed this limited usage of AAC to (i) difficulties with learning to use high-technology communication devices; (ii) a need for social closeness that may be a challenge when communicating via a speech-generating device; and (iii) a lack of training on AAC techniques and strategies. Earlier research also alluded to the low tolerance of persons with MND for any technology that requires extensive new learning as their physical functioning declines (Beukelman, Yorkston \& Dowden, 1985; Doyle \& Phillips, 2001).

Message banking, is an intervention strategy that requires little learning and could facilitate more effective communication for persons with MND (Costello, 2014). It consists of the recording of whole messages by the person with MND in his/her own natural voice and storing these electronically for later use. Given that message banking allows for recording legacy messages in one's own voice (Costello, 2014), its main aim is to maintain social closeness between the person with MND and his/her significant other. Message banking may not be confused with "voice banking", which refers to the process where large inventories of one's speech sounds are recorded to create a synthetic or computer voice that sounds like the person's own voice (Creer, Cunningham, Green, \& Yamagishi, 2013; Roy et al., 2006), technology that was originally developed in the 1980's (Yamagishi, Veaux, King \& Renals, 2012). Voice banking allows users to bank their voice for a time in the future when they need to use an AAC device. A text to speech synthesis voice can be created from these banked speech samples and used in a speech generating device as a personal voice (Mills, Bunnell, Patel, 2014). This technology is currently being widely investigated as it could allow for the development of personalized voice characteristics, and vocal identity which could possibly reduce social distance between communication partners (Yamagishi et al., (2010). The importance of voice as an identifying feature in terms of age gender, nationality, mood et centra, was recently highlighted by Nathanson (2017). Furthermore, the importance of 
emotional nuance in human speech was also emphasised (Pullin \& Hennig, 2015). .

Message banking for persons with MND focuses on the selection of vocabulary and messages to bank for future use in the persons own unique voice. Although speech-language pathologists (SLPs) play a pivotal role in message selection, the kind of messages that the person with MND and his/her significant others might want to have access to on the communication system should be discussed with all stakeholders. The MND partners (i.e. the person with MND, significant others and SLPs) all play an essential role in ensuring that adequate planning is done for message banking in the early stages of the disease, and such planning may improve the management of communication among them. A collaborative approach should be adopted by the MND partners to select messages for banking, because the successful use of AAC often depends on the partners' concerns, skills and preferences about AAC (Murphy, 2004).

The current study primarily aimed to determine and compare the perceptions about message banking of the MND partners (i.e. persons with MND, their significant others and practising SLPs). Second, the study aimed to determine the possible messages to record during message banking, based on the perspectives of these three stakeholder groups.

\section{Method}

\section{Research design}

The study used a comparative non-experimental group survey design (McMillan \& Schumacher, 2014). A questionnaire was specifically developed to determine participants' perceptions about message banking. Participants listened to a 6 minute 52 second presentation on message banking that was purposely developed for this study. After having listened to the presentation as a group, the persons with MND, their significant others and 
SLPs individually completed a questionnaire about their perceptions regarding message banking. Data were compared between the three stakeholder groups, and the similarities and differences of the perceptions being studied were highlighted.

\section{Participant recruitment}

Purposive sampling is a non-probability sampling method that was used to recruit participants on the basis of their accessibility (McMillan \& Schumacher, 2014). The persons with MND were recruited from the database of the Motor Neuron Disease Association of South Africa (MNDASA). The MNDASA provided a list of 28 potential participants who met the selection criteria, namely (i) diagnosed with mild to moderate MND by a neurologist; (ii) time after onset no longer than 15 years; (iii) lived in the same geographical area; (iv) literate in English; (v) able to independently and legibly complete a questionnaire in writing; and (vi) able to identify at least one significant other who would agree to participate in the study and who spends a minimum of three hours per week with the person with MND. Telephone calls were made to all 28 potential participants to inform them about the aim and nature of the study and invite them to attend the video screening and data collection. Ten participants declined participation. The other eighteen participants were interested and provided an email address, after which a formal invitation letter was sent to them.

The SLPs were recruited from the database of the South African Speech-LanguageHearing Association (SASHLA) and they met the following criteria: (i) they were registered with the Health Professions Council of South Africa; (ii) they worked in the specified geographical area; and (iii) they stated on the SASHLA database that they were interested in or currently providing intervention to persons with MND. Seventeen of the SLPs were informed via email of the date and time for data collection, and all attended. 


\section{Paricipant selection}

Eight of the eighteen persons with MND who were recruited to participate in this study were unable to attend for various personal reasons. Three participants responded that they were unable to attend due to difficulties with arranging transportation on the day specified for data collection. Fifteen participants were reminded telephonically a week in advance to confirm their attendance on the day of data collection. Two potential participants could not attend for unspecified reasons; one person could not attend due to hospitilization and two participants had passed away in the interim. This resulted in a total of ten persons with MND who agreed to participate in the study.

The ten persons with MND were requested to identify one significant other with whom they spend at least three hours a week, to also participate in the study. One of the persons with MND identified two significant others, and hence eleven significant others participated in the study.

\section{Participant Description}

The ten participants with MND who participated in this study was comprised of seven males and three females, which is typical of the reported male to female sex ratio of 1.5 to 2.1 up to the age of 70 years when the incidence rate becomes equal (Freed, 2000; Mitsumoto, 1997). The participants' ages ranged from $34 ; 10$ (years; months) to $77 ; 10$ years $(M=57 ; 23$ years), which is consistent with the peak of MND in the fifth and sixth decade of life (Chiò et al., 2004). The time since diagnosis was reported to be less than five years ( $M=4 ; 11$ years). Two persons with MND reported that they had not completed their high school education, while four participants had done so and three had also acquired a diploma. One person with MND did not specify the highest level of qualification obtained. Five of the persons with MND were married, four were unmarried or divorced, and one was widowed. Seven persons 
Running Head: MESSAGE BANKING: COMPARING PERCEPTIONS

Table I

Demographic data for persons with motor neuron disease $(n=10)$

\begin{tabular}{|c|c|c|c|c|c|c|c|c|c|c|}
\hline Sex & Age* & $\begin{array}{c}\text { Highest } \\
\text { qualification }\end{array}$ & $\begin{array}{c}\text { Year of } \\
\text { diagnosis }\end{array}$ & $\begin{array}{l}\text { Occupation / } \\
\text { previous } \\
\text { occupation }\end{array}$ & $\begin{array}{c}\text { First } \\
\text { language }\end{array}$ & $\begin{array}{c}\text { Marital } \\
\text { status }\end{array}$ & Living with & $\begin{array}{c}\text { Consulted } \\
\text { with a } \\
\text { speech } \\
\text { language } \\
\text { pathologist }\end{array}$ & $\begin{array}{c}\text { Severity of } \\
\text { speech } \\
\text { difficulties } \\
* *\end{array}$ & $\begin{array}{c}\text { State of } \\
\text { classification } \\
\text { of MND } \\
\text { (Reviere et } \\
\text { al., 1998)** }\end{array}$ \\
\hline $\mathrm{F}$ & $56 ; 08$ & Diploma & 2015 & Teacher & English & Widowed & Alone & No & 2 & 3 \\
\hline M & $58 ; 10$ & Grade 12 & 2013 & Mine worker & English & Married & Wife & Yes & 1 & 3 \\
\hline M & $52 ; 07$ & Below Grade 12 & 2014 & Not specified & English & Unmarried & Ex-wife & No & 1 & 1 \\
\hline M & $52 ; 10$ & Diploma & 2015 & Foreman & Afrikaans & Married & Wife & No & 3 & 2 \\
\hline $\mathrm{F}$ & $74 ; 05$ & Grade 12 & 2000 & Not specified & English & Unmarried & $\begin{array}{l}\text { Retirement } \\
\text { home }\end{array}$ & No & 2 & 3 \\
\hline $\mathrm{F}$ & $53 ; 08$ & Diploma & 2015 & $\begin{array}{l}\text { Market } \\
\text { manager }\end{array}$ & Afrikaans & Unmarried & Alone & No & 3 & 2 \\
\hline M & $77 ; 11$ & Not specified & 2015 & $\begin{array}{l}\text { Minister of } \\
\text { religion }\end{array}$ & English & Married & Wife & Yes & 1 & 1 \\
\hline
\end{tabular}

*Age is reflected in years; months

**Speech and motor neuron severity with $1=$ mild, $2=$ moderate $3=$ severe 
with MND were living with their spouses, partners or former spouses, while two were living alone and one lived in a retirement home. Only three persons with MND had reportedly consulted an SLP after being diagnosed with MND.

The first author and trained researched assistant independently rated the speech intelligibility of the participants using the Stages of Dysarthria System (Mathy, Yorkston \& Guttman, 2000) with 100\% agreement. The research assistant was an SLP with five years' experience of working with persons with MND. Five persons with MND had no detectable speech difficulties; two had obvious changes in their speech although it was still comprehensible. The speech intelligibility of the remaining three persons with MND was reduced. Regarding the classification of MND (Riviere, Meininger, Zeisser \& Munsat, 1998), severity was classified as mild for three participants, moderate for three, and severe for four.

A total of eleven significant others participated in the study. Eight of them were female, and three were male. Their ages ranged from $18 ; 1$ to $71 ; 6$ years old ( $M=49 ; 9$ years). The sample consisted of six spouses, two former spouses, two children and one friend. Six significant others, who were spouses or ex-spouses reported spending all their time with the person with MND. Two significant others reported spending five to ten hours a day with the person with MND; one spent two days a week and two spent three to five hours a week with the person with MND.

The SLPs $(n=17)$ were all female, which is common in South Africa (Pillay, Kathard \& Samuel, 1997). Ten SLPs had experience with persons with MND, while seven had no experience in this area. As all SLPs are qualified to work with adult neurogenic disorders, it was decided that all 17 participants could potentially have persons with MND on their case load and could thus provide valuable data. The ages of the SLPs ranged from 23.0 to 65.7 years $(M=32.8$ years $)$. 
Running Head: MESSAGE BANKING: COMPARING PERCEPTIONS

Table II

Demographic data for significant others $(n=11)$

\begin{tabular}{|c|c|c|c|c|c|}
\hline Sex & Age $*$ & $\begin{array}{l}\text { Relationship } \\
\text { to persons } \\
\text { with motor } \\
\text { neuron disease }\end{array}$ & $\begin{array}{l}\text { Highest level of } \\
\text { education }\end{array}$ & Occupation & $\begin{array}{c}\text { Amount of time } \\
\text { spent with persons } \\
\text { with motor neuron } \\
\text { disease }\end{array}$ \\
\hline $\mathrm{F}$ & $60 ; 11$ & Friend & Honours & Social worker & 2 days per week \\
\hline $\mathrm{F}$ & $49 ; 02$ & Spouse & Diploma & Housewife & 24 hours a day \\
\hline M & $44 ; 02$ & Ex-husband & Grade 12 & Senior clerk & $\begin{array}{l}\text { All except working } \\
\text { hours }\end{array}$ \\
\hline $\mathrm{F}$ & $38 ; 05$ & Spouse & Diploma & Bookkeeper & $\begin{array}{l}\text { All except working } \\
\text { hours }\end{array}$ \\
\hline $\mathrm{F}$ & $51 ; 03$ & Spouse & Diploma & Teacher & 5 hours per day \\
\hline $\mathrm{F}$ & $18 ; 01$ & Child & Grade 12 & Not specified & 10 hours per day \\
\hline $\mathrm{F}$ & $38 ; 07$ & Spouse & Grade 12 & Unemployed & 24 hours a day \\
\hline $\mathrm{F}$ & $68 ; 08$ & Spouse & Below Grade 12 & Housewife & 24 hours a day \\
\hline M & $55 ; 06$ & Ex-husband & Diploma & Own business & 3-5 hours per week \\
\hline M & $53 ; 05$ & Child & Grade 12 & Consultant & 4-5 hours per week \\
\hline $\mathrm{F}$ & $71 ; 06$ & Spouse & Diploma & Retired & 24 hours a day \\
\hline
\end{tabular}

*Age is reflected in years; months 
Table III

Demographic data for speech-language pathologists $(n=17)$

\begin{tabular}{cllcc}
\hline Sex & Age * & Highest qualification & $\begin{array}{c}\text { Number of years as a } \\
\text { qualified speech language } \\
\text { pathologist }\end{array}$ & $\begin{array}{c}\text { Experience with persons } \\
\text { with motor neuron } \\
\text { disease }\end{array}$ \\
\hline F & $26 ; 01$ & Bachelor's degree & 4 years & Yes \\
F & $53 ; 00$ & Bachelor's degree & 29 years & Yes \\
F & $65 ; 07$ & Master's degree & 42 years & Yes \\
F & $24 ; 11$ & Bachelor's degree & 2 years & No \\
F & $33 ; 01$ & Master's degree & 13 years & Yes \\
F & $28 ; 00$ & Bachelor's degree & 5 years & Yes \\
F & $37 ; 09$ & Master's degree & 15 years & No \\
F & $26 ; 06$ & Bachelor's degree & 3 years & Yes \\
F & $25 ; 09$ & Bachelor's degree & 9 months & No \\
F & $30 ; 01$ & Bachelor's degree & 9 years & Yes \\
F & $44 ; 06$ & Master's degree & 22 years & Yes \\
F & $26 ; 03$ & Bachelor's degree & 3 years & No \\
F & $30 ; 06$ & Bachelor's degree & 7 years & No \\
F & $25 ; 01$ & Bachelor's degree & 3 years & No \\
F & $23 ; 00$ & Bachelor's degree & 9 months & Yes \\
F & $31 ; 00$ & Master's degree & 8 years & No \\
F & $28 ; 01$ & Bachelor's degree & 5 years & Yes \\
\hline
\end{tabular}

*Age is reflected in years; months 


\section{Materials}

Message banking video presentation and pamphlet. A custom-designed video presentation was developed to inform participants about message banking and how it is done. (This video is available at https://voice.adobe.com/a/PNpRA for free download.) The video was developed by the first author, a speech pathologist with experience working with people with MND. The remaining authors assisted with the development of the script and refinement of the video. The video was viewed and input from SLPs, persons with MND and their SO were obtained as well following the pilot study. In addition, a pamphlet, based on the video, was designed to provide the participants with written information about message banking.

Message banking questionnaire. The message banking questionnaire was custom designed and piloted to determine the participants' perceptions of message banking. These are avaible upond request from the authors. The same questionnaire was used for all three stakeholder groups and only minor adaptions specific to the participant group were made, e.g. change of pronouns. The questionnaire consisted of three sections. Section 1 focused on knowledge of AAC, including awareness and current use of AAC strategies. Section 2 focused on perceptions about message banking, including awareness about, perceived relevance of, and interest in message banking. Section 3 was based on the Communication Device Use Checklist (Fried-Oken et al., 2006), which was adapted for this study to determine which messages participants would want in the natural voice of the person with MND and which in a digital voice. Available as supplementary files.

\section{Procedures}

Ethics approval was obtained from the relevant institute of higher education. Permission was also obtained from MNDASA to assist with the recruitment of potential participants from the database. Written informed consent to participate in the study was 
obtained from all potential participants.

\section{Data collection for persons with MND and significant others}

Data were collected during two separately scheduled sessions. Five persons with MND and their significant others attended each of the sessions. On arrival, participants were welcomed by the first author and research assistant. A set of instructions was developed that outlined the data collection procedures in order to strengthen procedural integrity. Biographical questionnaires were distributed to all participants, and they were requested to complete the questionnaire in writing. The handwriting of the persons with MND on the biographical information questionnaire was screened for legibility, and the severity of MND (Riviere et al., 1998) was determined for each participant.

Persons with MND and their significant others watched the video presentation about message banking. After the presentation, data collection commenced. Persons with MND and their significant others were presented with the message banking questionnaire, which they completed independently. Participants were not able to view one another's responses. After the questionnaires had been completed, the message banking pamphlet was distributed to the participants for their personal use. Participants were thanked for their participation. A question-and-answer session and support group meeting followed.

\section{Data collection for SLPs}

SLPs were informed via email of the date for data collection. All of the potential 17 SLPs voluntarily consented to participate in the study. The data collection procedures for SLPs were exactly as described for the persons with MND, except that data collection occurred in a single session. Upon arrival, they watched the video presentation and then completed the biographical and message banking questionnaire. Next, the message banking 
pamphlet was provided to each participant, followed by a two-hour presentation of SLP management strategies for persons with MND as part of continued professional education.

\section{Data analysis}

Descriptive statistics were computed to determine and compare the various perceptions. Comparisons between participant groups were made using non-parametric statistics. The Mann-Whitney $U$ test was used to compare ordinal variables in two independent groups; the Kruskal-Wallis $\mathrm{H}$ test was adopted to make comparisons across the three groups of participants; and the one-tailed Fisher's Exact Test was used to compare categorical variables. Finally, chi-square test was used as it is a frequency measure for nominal variables comparing independent groups. The statements provided by persons with MND and their significant others were coded according to the four communication purposes proposed by Light (1988), namely communication of needs and wants; information transfer; social closeness; and social interaction. One monthafter the original coding, the first author re-coded the messages and intra-rater reliability was found to be $100 \%$.

\section{Result}

The results of the study present data for AAC awareness, perceptions about message banking, communication purposes for message banking, and finally, the categories of messages that should be banked.

\section{Awareness of AAC}

A high number of SLPs - 16 out of $17(94 \%)$ - were aware that AAC strategies could be used for persons with MND. It is, however, noteworthy that only 47\% $(n=7)$ of these SLPs actually recommended AAC strategies when working with persons with MND, even though 94\% $(n=16)$ of SLPs were aware that AAC strategies could be used for these persons once their speech became compromised. SLPs reported that their management of persons 
Table IV

$A A C^{*}$ awareness and perceptions about message banking

\begin{tabular}{|c|c|c|c|}
\hline Area & $\begin{array}{l}\text { Persons with } \\
\text { motor neuron } \\
\text { disease } \\
(n=10)\end{array}$ & $\begin{array}{c}\text { Significant } \\
\text { others } \\
(n=11)\end{array}$ & $\begin{array}{c}\text { Speech } \\
\text { language } \\
\text { pathologist } \\
(n=17)\end{array}$ \\
\hline \multicolumn{4}{|l|}{ Awareness of AAC } \\
\hline Never heard of AAC & 5 & 5 & 0 \\
\hline Heard but knew nothing about AAC & 2 & 3 & 0 \\
\hline Know a little about AAC & 2 & 2 & 9 \\
\hline Know a fair amount about AAC & 1 & 1 & 7 \\
\hline Know a lot about AAC & 0 & 0 & 1 \\
\hline \multicolumn{4}{|l|}{ Perceptions of message banking } \\
\hline Informed by SLP & 2 & 3 & 0 \\
\hline Never heard of message banking & 7 & 6 & 6 \\
\hline Heard but know nothing about message banking & 2 & 3 & 4 \\
\hline Know a little about message banking & 0 & 2 & 4 \\
\hline Know a fair amount about message banking & 1 & 1 & 2 \\
\hline Know a lot about message banking & 0 & 0 & 0 \\
\hline $\begin{array}{l}\text { Message banking should commence as soon as } \\
\text { possible after diagnosis }\end{array}$ & 5 & 7 & 17 \\
\hline $\begin{array}{l}\text { Message banking should commence once speech } \\
\text { starts changing }\end{array}$ & 3 & 3 & 0 \\
\hline When SLP recommends it & 1 & 0 & 0 \\
\hline Unsure & 1 & 1 & 0 \\
\hline \multicolumn{4}{|l|}{ Perceptions of message banking* } \\
\hline Too expensive & 2 & 2 & 11 \\
\hline Too time consuming & 0 & 1 & 5 \\
\hline Too difficult & 1 & 0 & 5 \\
\hline Interested in message banking & 8 & 4 & 17 \\
\hline
\end{tabular}

*Augmentative and Alternative Communication

**Please note that the participants could indicate as many options as they wished. 
with MND primarily included treatment of dysphagia $(n=15)$; improving articulation $(n=$ 12); improving respiration ( $n=9)$; improving phonation and prosody $(n=7)$, as well as improving resonance $(n=4)$.

Substantive knowledge about AAC was rare, with only one of 10 people with MND, one of 11 significant others, and one of 17 SLPs indicating that they knew a lot about AAC (see Table IV).

\section{Perceptions about message banking}

Persons with MND had fewer negative than positive perceptions about message banking. However, this was not the case for all participant groups. A statistically significant difference $\chi^{2}(1, n=37)=9.65, p=.008$ was found between SLPs and significant others when a chi-square test was used to compare their perceptions about the cost of message banking. The SLP group considered message banking to be expensive when compared to the significant others group. Similarly, statistically significant differences occurred between significant others and SLPs $(\mathrm{p} \leq 0.05)$ regarding the difficulty of the task $\chi^{2}(1, n=27)=$ $6.42, p=.040$ was found, with significant others finding it more diffiuclt when compared to the SLP group.

Participants had different views about the relevance of message banking, Statistically significant differences $(p \leq 0.05)$ were found for persons with MND and their significantothers $\chi^{2}(1, n=37)=5.28, p=037$. Persons with MND perceived message banking to be more relevant than significant others did.

\section{Communication purposes of message banking}

Persons with MND and significant others were asked to provide the first author with a list of messages that they thought would be important to record in the person with MND's 
own words during message banking. Participants' sentences were subsequently grouped according to the four purposes of communication as defined by Light (1988), as mentioned earlier.

Persons with MND provided 69 sentences. Most persons with MND wanted to bank sentences about social closeness (33\% of messages were categorized as messages about social closeness); followed by messages about needs and wants (20\%); social etiquette (15\%); and lastly messages about information transfer (11\%).

When significant others were asked what they would like their partner to bank, they provided 66 messages. The frequency of suggested sentences was similar but their purposes differed noticeably. Most wanted their significant other with MND to bank messages about needs and wants (44\%), followed by social closeness (26\%) and information transfer messages (23\%), and only $8 \%$ wanted them to bank messages about social etiquette. Reverse patterns were seen for the two most important purposes (social closeness and needs and wants) for persons with MND and significant others, as well as for the two least important purposes (social etiquette and information transfer).

\section{Categories of messages to bank in the voice of the person with MND}

Figure 1 illustrates the great variety in the messages that participants from the three stakeholder groups considered as important to bank in the natural voice of the person with MND. Participants in the study were also asked which categories of messages would be acceptable in a computer voice (synthetic voice) and for which categories they thought their own voice / the voice of the person with MND would be crucial. The categories are based on the Communication Device Use Checklist (Fried-Oken et al., 2006). Not all participants provided answers in each category, which caused the group size to vary for each category. 
Running Head: MESSAGE BANKING: COMPARING PERCEPTIONS

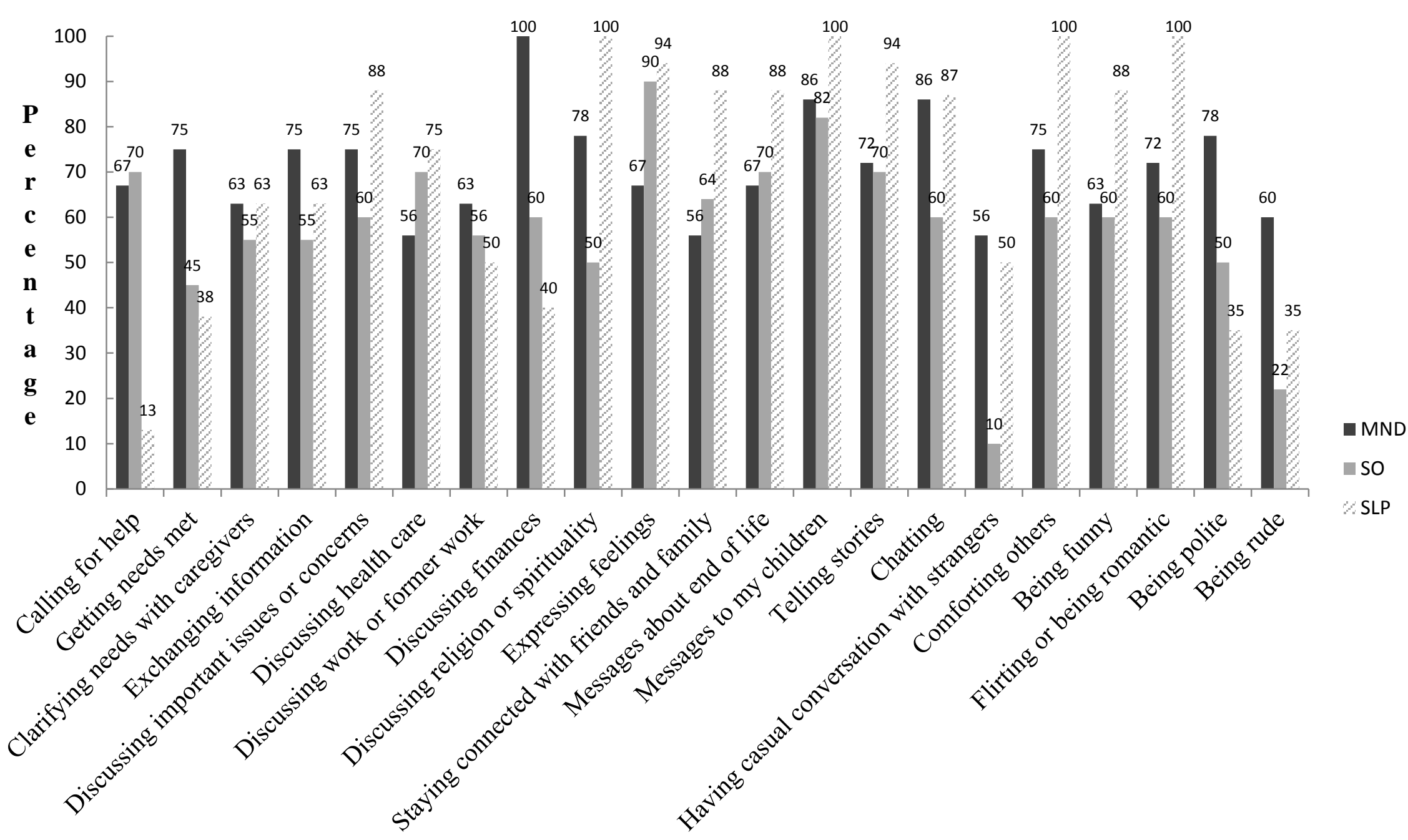

Figure 1 Percentage of persons with motor neuron disease (MND), significant others (SO), and speech-language pathologists (SLPS) who selected messages as important to bank in the voice of the person with MND 
Persons with MND indicated that one of the most important areas that they wanted to bank in their own voice related to discussions about their finances (see Figure 1). Despite the fact that all participants felt religion or spirituality was important, the chi-square test revealed statistically significant differences $\chi^{2}(2, n=36)=12.07, p=.002$ between all three groups. All three stakeholder groups also considered messages to comfort others as important to bank in the voice of the person with MND. However, the chi-square test revealed statistically significant differences between the SLP group and the significant others group $\chi^{2}(2, n=35)$ $=9.61, p=.008$. All three groups considered messages that would enable the person with MND to continue flirting or be romantic as important. However, the SLP group considered these messages significantly important when between to the significant others $\chi^{2}(2, n=34)$ $=9.9, p=.007$.

\section{Discussion}

\section{Perceptions about AAC and message banking}

The majority (90\%) of persons with MND who participated in this study still had intelligible speech at the time of data collection, which made them potential candidates for early message banking. However, the results indicate that participants across all three groups had limited knowledge about message banking. The low levels of awareness of AAC among persons with MND and significant others in this study are of concern, given the fact that research indicates that $95 \%$ of those diagnosed with MND will lose the ability to meet their daily communication needs with their natural speech (Mckelvey et al., 2012). Recent research about changes in communication needs and strategies during MND progression also suggests that newer technologies may make it possible even for people with end-stage MND to continue communicating effectively (Ball et al., 2010). 
An alarming finding was that a third of the SLPs who participated in the study had never heard of message banking before this study. Seeing that most people with MND hear about AAC strategies from SLPs, it is inevitable that the latter's lack of knowledge would cause persons with MND and their significant others to also have low levels of awareness about message banking. Although some of the SLPs were aware of AAC strategies, very few recommended AAC strategies for their clients with MND. The emphasis that SLPs in this study placed on management of speech strengthening and improvement is contrary to current evidence in the literature. In a review examining AAC patterns and use for persons with MND, Hanson (2014) could not find evidence to support the use of speech-strengthening or speech improvement exercises (i.e. improving articulation, respiration, phonation, prosody and resonance) for persons with MND.

\section{Timing of message banking}

There is a paucity of research about message banking, which may explain the low awareness levels of message banking for people with MND. The importance of early intervention for people with MND is, however, emphasised in the literature (Yorkston, Strand, Miller, Hillel \& Smith, 1993). Persons with MND and their significant others involved in the current study had views that differed from SLPs about the timing of message banking. The problem is that it may seem unrealistic to prepare for speech changes when no symptoms are evident. Therefore, SLPs are ethically bound to recommend that message banking should start as soon as possible, even when many persons with MND and their significant others prefer to refuse to consider this step. SLPs must provide the necessary support and help them to adjust to the thought of message banking soon after the diagnosis.

\section{Relevance of message banking}

It is noteworthy that the participants with MND perceived message banking as equally 
relevant for themselves and for other persons with MND in general. Significant others, however, perceived message banking to be much less relevant for both persons with MND in general and their own significant other with MND. A statistically significant difference was found between the responses of persons with MND and those of their significant others

$p \leq 0.05$. Research findings suggest that the perceptions and attitudes of family members towards technology could well be a barrier to the implementation of message banking. Hence, one must highlight the importance of a collaborative effort between a person with communication difficulties and his/her significant other, resulting in shared responsibility between them for communication (Brownlee \& Breunning, 2012). Successful use of AAC often depends on the different partners' concerns and preferences about AAC, as well as their skills with regard to AAC use (Brownlee \& Breunning, 2014).

\section{Negative perceptions about message banking}

The negative perceptions towards message banking revealed by the current study were not surprising. The opinion in current literature is that no matter how advanced technology is, it can never replace the voice, fingers or legs of the person with MND (Beukelman et al., 2011). Given the steady decline in their physical functioning, persons with MND often have little tolerance for any technology that requires extensive new learning (Beukelman et al., 2011; Brownlee \& Breunning, 2012). The generally negative perceptions of the significant others and SLP groups could be an indicator of barriers to successful implementation of message banking, which highlights the need to train SLPs in particular on aspects such as the costs involved, difficulty and process of message banking. Information regarding the use of message banking with a cellular phone, which is both cost efficient and easy to use, needs to be shared with SLPs. Significant others also require accurate information, as family perceptions and support have been identified as one of the three major barriers to successful AAC implementation (Baxter, Enderby, Evans \& Judge, 2012). 


\section{Communication purposes of message banking}

The findings in this study regarding the communication purposes of message banking as indicated by significant others are consistent with those of Fried-Oken et al. (2006), namely that caregivers reported that persons with MND use AAC to get their needs met, to achieve social closeness and to transfer information. Results about the communication purposes of message banking as identified by those with MND are also supported in the literature. Costello (2014) states that message banking allows for social closeness as it enables the persons with MND to record legacy messages. Furthermore, the significant others in the study by Fried-Oken et al. (2006) reported that persons with MND regard the ability to maintain social closeness with another person as the most important purpose of communication. They rate it higher than their desire to indicate wants and needs or to pass on information (Fried-Oken et al., 2006). In the current study, persons with MND, also regarded information transfer as the least important communication purpose ith social etiquette as more important. The focus on social closeness is also supported by Stuart, Lasker and Beukelman (2000) who suggest that at all stages of the disease, the person with MND might need vocabulary to conserve 'small talk' and maintain social closeness.

\section{Categories of messages to bank in the natural voice of persons with MND}

Persons with MND rated messages about discussing finances (information transfer) as the highest category for which they wanted messages in their voice. This was significantly different from the SLPs' rating in this category. Social closeness constituted the second-most important group of categories in which persons with MND wanted to record messages in their own voice (i.e. messages to children and chatting).

The categories of messages that SLPs selected as important to bank in the voice of the persons with MND differed from those indicated by the persons with MND themselves. The categories that SLPs selected as important were discussing religion and spirituality 
(exchanging information), messages to children, comforting others, and flirting or being romantic (social closeness). There were statistically significant differences between SLPs and persons with MND and their significant others, as evidenced by the Kruskal-Wallis tests, on the messages related to spirituality. SLPs and their significant others also differed significantly on messages about flirting or being romantic.

Persons with MND and their significant others can be expected to rely on SLPs for guidance about message banking. As communication is a collective effort and that it is imperative that all members of the AAC team agree on the value of the AAC technology and strategies (Ball \& Lasker, 2013). However, before any form of AAC is initiated, it is imperative that the person with MND should be allowed to reflect on and discuss his/her own goals for intervention (Brownlee \& Breunning, 2012). For the process of message banking, guidance about possible vocabulary and messages to bank for future use is of fundamental importance. SLPs should take sufficient time to talk through the kind of messages the person with MND might want to record. This will depend on many factors, not least of which will be the stage of the disease.

\section{Limitations and future directions}

The limitations of the study relate to the relatively small sample size, which caused the findings of the study to have limited generalisability. Unfortunately comparisons could also not be made between stakeholder groups consisting of a person with MND, his/her significant other(s) and an SLP, as only two of the participants with MND had consulted an SLP. Comparisons were therefore drawn between the three groups in general.

One of the recommendations for future research includes the exploration of the perceptions about message banking of persons with MND who are no longer able to speak or 
write, as their retrospective perceptions will be valuable guidance for those participants who are in the early stages of such a degenerative disorder.

It is further recommended to determine the attitudes of familiar listeners when message banking is used in conjunction with a synthetic voice on the AAC device. This study should compare messages spoken in a synthetic voice with messages spoken from the directory of messages banked by the person with MND, e.g. by emphasising a cross-over design.

\section{Conclusion}

The current study should be seen as a first step towards understanding the existing perceptions of three stakeholder groups about message banking. Firstly, awareness about $A A C$ was found to be similar for persons with MND and their significant others. In this study, AAC strategies were not widely used by the participants with MND, as $90 \%$ of them still had intelligible speech. Even though most SLPs were aware of AAC strategies for persons with MND, less than half of them were recommending AAC strategies to their clients with MND. Secondly, awareness about message banking was similar across all groups. Although the majority of participants in all three groups had never heard of message banking, the majority of them felt that the best time to start message banking was as soon as possible after diagnosis. Persons with MND had more positive perceptions towards message banking than did their significant others or SLPs. SLPs had the most negative perceptions towards message banking, including that it would be too expensive, too time consuming and too emotional for the persons with MND whom they saw at their practice. Thirdly, an interest in message banking was prevalent among the majority of persons with MND and SLPs involved in the study. 
Finally, differences about the types of messages that were important to bank were found between persons with MND and their significant others. Also, the categories of messages that SLPs selected as important to bank in the voice of the person with MND differed somewhat from those selected by the participants with MND. Although the specific categories differed, social closeness was considered the most important communication purpose for all participant groups.

The most significant clinical implication of this study is the fact that it demonstrated that SLPs and significant others potentially have different perceptions about message banking than the persons with MND themselves. SLPs should take care not to assume that their perceptions are necessarily similar to those of the persons with MND or their significant others. Also, clinical implications for message banking are that the communication purposes seen as most important for message banking are social closeness and the expression of needs and wants. These categories should consequently be explored when advising persons with MND on the messages to include for message banking.

\section{References}

American Speech-Language-Hearing Association. (2001). Scope of practice in speechlanguage pathology. Rockville, MD: Author: Amyotrophic Lateral Sclerosis (ALS). Retrieved on 5 November 2015.

Ball, L. J., Beukelman, D. R., \& Pattee, G. L. (2004). Acceptance of augmentative and alternative communication technology by persons with amyotrophic lateral sclerosis. Augmentative and Alternative Communication, 20(2), 113-122. http://dx.doi.org/10.1080/0743461042000216596 
Ball, L. J., \& Lasker, J. (2013). Teaching partners to support communication for adults with acquired communication impairment. Perspectives on Augmentative and Alternative Communication, 22, 4-15. http://dx.doi.org/10.1044/aac22.1.4

Ball, L .J., Nordness, A., Fager, S. K., Kersch, K., Mohr, B., Pattee, G. L., \& Beukelman, D. R. (2010). Eye-gaze access of AAC technology for persons with amyotrophic lateral sclerosis. Journal of Medical Speech-Language Pathology, 18, 11-23.

Baxter, S., Enderby, P., Evans, P., \& Judge, S. (2012). Barriers and facilitators to the use of high-technology augmentative and alternative communication devices: A systematic review and qualitative synthesis. International Journal of Language \& Communication Disorders, 47, 115-129. http://dx.doi.org/10.1111/j.14606984.2011.00090.x

Beukelman, D. R., Fager, S., Ball, L., \& Dietz, A. (2007). AAC for adults with acquired neurological conditions: A Review. Augmentative and Alternative Communication, 23(3), 230-242. http://dx.doi.org/10.1080/07434610701553668

Beukelman, D. R., Fager, S., \& Nordness, A. (2011). Communication support for people with ALS. Neurology Research International. doi: 10.1155/2011/714693.

Beukelman D., Yorkston, K., \& Dowden, P. (1985). Communication augmentation: A casebook of clinical management. San Diego: College-Hill.

Brownlee, A. (2014). Augmentative Communication. Retrieved on 11 November 2015, from http://www.alsa.org/als-care/augmentative-communication/.

Brownlee, A., \& Bruening, L. M. (2012). Methods of communication at end of life for the person with amyotrophic lateral sclerosis. Topics in Language Disorders, 32, 168185.

Bongioanni, P. (2012). Communication Impairment in ALS Patients' Assessment and Treatment. INTECH Open Access. 
Costello, J. (2014). Boston Children's Hospital Message Banking examples from people with ALS. (2014). Retrieved on 25 June 2014 from https://www.childrenshospital.org/ /media/f670672fe0574861b827a98f8b2551f8.ash $\mathrm{X}$.

Creer, S., Cunningham, S., Green, P., \& Yamagishi, J. (2013). Building personalised synthetic voices for individuals with severe speech impairment. Computer Speech \& Language, 27(6), 1178-1193.

Doyle, M., \& Phillips, B. (2001). Trends in augmentative and alternative communication use by individuals with amyotrophic lateral sclerosis. Augmentative and Alternative Communication, 17(3), 167-178. http://dx.doi.org/10.1080/aac.17.3.167.178

Freed, D. (2000). Motor speech disorders: Diagnosis and treatment. San Diego: Singular Publishing.

Fried-Oken, M., Fox, M., Rau, M. T., Tullman, J., Baker, G., Hindal, M., Wile, N., \& Lou, J. (2006). Purposes of AAC device use for persons with ALS as reported by caregivers. Augmentative and Alternative Communication, 22(3), 209-221. http://dx.doi.org/10.1080/07434610600650276

Hardiman, O., van den Berg, L. H., \& Kiernan, M. C. (2011). Clinical diagnosis and management of amyotrophic lateral sclerosis. Nature Reviews Neurology, 7(11), 639649. http://dx.doi.org/10.1038/nrneurol.2011.153

Henning, F. (2012). Thumbs Up: The newsletter of the Motor Neurone Disease / Amyotrophic Lateral Sclerosis Association of South Africa. Media Print. Retrieved from http://www.mnda.org.za/NL/October\%202014.pdf

Hanson, E. K. (2014). Dysarthria in ALS: A systematic review of characteristics in speech treatment, and AAC options. Journal of Medical Speech-Language Pathology, 19(3), 12-13. http://dx.doi.org/10.1044/nnsld23.3.120 
Light, J. (1988). Interaction involving individuals using augmentative and alternative communication systems: State of the art and future directions, Augmentative and Alternative Communication, 4(2), 66-82. http://dx.doi.org/10.1080/07434618812331274657

Mathy, P., Yorkston, K. M., \& Gutmann, M. L. (2000). AAC for individuals with amyotrophic lateral sclerosis. In D. R. Beukelman, K. M. Yorkston, \& J. Reichle (Eds.), Augmentative and alternative communication for adults with acquired neurological disorders (pp. 183-232). Baltimore: Paul H. Brookes.

Mckelvey, M., Evans, D. L., Kawai, N., \& Beukelman, D. (2012). Communication styles of persons with ALS as recounted by surviving partners. Augmentative and Alternative Communication, 28(4), 232-242. http://dx.doi.org/10.3109/07434618.2012.737023

McMillan, J. H., \& Schumacher, S. (2014). Research in education: A conceptual introduction (7th ed.). New York: Addison Wesley Longman.

Mitsumoto, H. (1997). Diagnosis and progression of ALS. Neurology, 48 (Suppl 4), S2-S8. http://dx.doi.org/10.1212/wnl.48.4_suppl_4.2s

Mills, T., Bunnell, H. T., \& Patel, R. (2014). Towards personalized speech synthesis for augmentative and alternative communication. Augmentative and Alternative Communication, 30(3), 226-236. http://dx.doi.org/10.3109/07434618.2014.924026

Murphy, J. (2004). "I prefer contact this close": Perceptions of AAC by people with motor neuron disease and their communication partners. Augmentative and Alternative Communication, 20(4), 259-271. http://dx.doi.org/10.1080/07434610400005663

Nathanson, E. (2017). Native voice, self-concept and the moral case for personalized voice technology. Disability and rehabilitation, 39(1), 73-81. http://dx.doi.org/10.3109/09638288.2016.1139193 
Pillay, M., Kathard, H., \& Samuel, M. A. (1997). The curriculum of practice: A conceptual framework for speech-language therapy and audiology practice with a black African first language clientele. Die Suid Afrikaanse Tydskrif vir Kommunikasieafwykings, 44.

Pullin, G., \& Hennig, S. (2015). 17 Ways to Say Yes: Toward Nuanced Tone of Voice in AAC and Speech Technology. Augmentative and Alternative Communication, 31(2), 170-180. http://dx.doi.org/10.3109/07434618.2014.924026

Pupillo, E., Messina, P., Logroscino, G., \& Beghi, E. (2014). Long-term survival in amyotrophic lateral sclerosis: A population-based study. Annals of Neurology, 75(2), 287-297. doi:10.1002/ana.24096. http://dx.doi.org/10.1002/ana.24096

Riviere, M., Meininger, V., Zeisser, P., \& Munsat, T. (1998). An analysis of extended survival in patients with amyotrophic lateral sclerosis treated with riluzole. Archives of Neurology, 55(4), 526-528. http://dx.doi.org/10.1001/archneur.55.4.526

Roy, D., Patel, R., DeCamp, P., Kubat, R., Fleischman, M., Roy, B., ... \& Levit, M. (2006). The human speechome project. In Symbol Grounding and Beyond (pp. 192-196). Springer Berlin Heidelberg.

Stuart, S., Lasker, J., \& Beukelman, D. (2000). AAC message management. In D. Beukelman, K. Yorkston, \& J. Reichle (Eds.), Augmentative communication for adults with neurologic disorders, pp. 25-54. Baltimore, MD: Paul H. Brookes.

Yamagishi, J., Veaux, C., King, S., \& Renals, S. (2012). Speech synthesis technologies for individuals with vocal disabilities: Voice banking and reconstruction. Acoustical Science and Technology, 33(1), 1-5. http://dx.doi.org/10.1250/ast.33.1

Yorkston, K. M., Strand, E., Miller, R. M., Hillel, A. D., \& Smith, K. (1993). Speech deterioration in amyotrophic lateral sclerosis: Implications for the timing of intervention. Journal of Medical Speech-Language Pathology, 1(1), 35-46. http://dx.doi.org/10.1044/1058-0360.0404.139 